NASA Technical Memorandum 100631

FLEXIBLE BACKBONE AROMATIC POLYIMIDE ADHESIVES

DONALD J. PROGAR AND TERRY L. ST, CLAIR 


\section{FLEXIBLE BACKBONE AROMATIC POLYIMIDE ADHESIVES}

Donald J. Progar and Terry L. St. Clair

Polymeric Materials Branch, NASA Langley Research Center, Hampton, VA 23665-5225

Continuing research at Langley Research Center on the synthesis and development of new inexpensive flexible aromatic polyimides as adhesives has resulted in a material identified as $\mathrm{LARC}-\mathrm{F}-\mathrm{SO}_{2}$ with similarities to polyimidesulfone, $\mathrm{PISO}_{2}$, and other flexible backbone polyimides recently reported by Progar and St. Clair. Also prepared and evaluated was an endcapped version of $\mathrm{PISO}_{2}$. These two polymers were compared with LARC-TPI and LARC-STPI, polyimides researched in our laboratory and reported in the literature.

The adhesive evaluation, primarily based on lap shear strength (LSS) tests, involved preparing adhesive tapes, conducting bonding studies and exposing lap shear specimens to $204^{\circ} \mathrm{C}$ air for up to $1000 \mathrm{hrs}$ and to a 72-hour water boil. LSS tests at RT, $177^{\circ} \mathrm{C}$ and $204^{\circ} \mathrm{C}$ were performed before (controls) and after these exposures. The type of adhesive failure as well as the $\mathrm{Tg}$ was determined for the fractured specimens.

The results indicate that LARC-TPI provides the highest LSSs, 33 MPa at RT, $30 \mathrm{MPa}$ at $177^{\circ} \mathrm{C}$, and $26 \mathrm{MPa}$ at $204^{\circ} \mathrm{C}$. LARC-F-SO $\mathrm{S}_{2}, \mathrm{LARC}-\mathrm{TPI}$ and LARC-STPI all retain their strengths after thermal exposure for $1000 \mathrm{hrs}$ and $\mathrm{PISO} 2$ retains greater than $80 \%$ of its control strengths.

Most of the four adhesive systems showed reduced strengths for all test temperatures although still retaining a high percentage of their original strength (> 60\%) except for one case. 
The predominant failure mode was cohesive with no significant change in the Tgs.

Although the LARC-F-SO 2 could not be prepared in diglyme alone as the solvent, the properties of the resulting adhesive were notable. The darkening of the adhesive during bonding was typical of systems which utilize amide solvents.

\section{INTRODUCTION}

During the past decade, considerable research at NASA Langley Research Center has been directed towards the synthesis of flexible aromatic polyimides. ${ }^{1-7}$ Two notable polyimides that are now commercially available resulted from this work. They are LARC-TPI and polyimidesulfone $\left(\mathrm{PISO}_{2}\right) .{ }^{5}, 7$ Both of these polyimides contain bridged aromatic diamines with meta catenation as described by Bell, et al. 1 Recently Progar and St. Clair reported on two flexible backbone copolyimides that were synthesized in an effort to develop a relatively inexpensive high temperature adhesive. ${ }^{6,8}$ These polymers contained the diamines 4,4'-diaminodiphenylether (commonly referred to as oxydianiline or ODA) and meta phenylenediamine (MPD). The combined use of these two compounds afforded adhesives with attractive properties. Research of a similar nature continues in our laboratory with the development of a new copolyimide with structural similarities to PISO2. This material, designated as $L A R C-F-\mathrm{SO}_{2}$, is shown below.

This paper compares the novel LARC-F-SO 2 to its progenitors, $\mathrm{PISO}_{2}$, LARC-STPI flexible copolyimide and LARC-TPI polymer. 


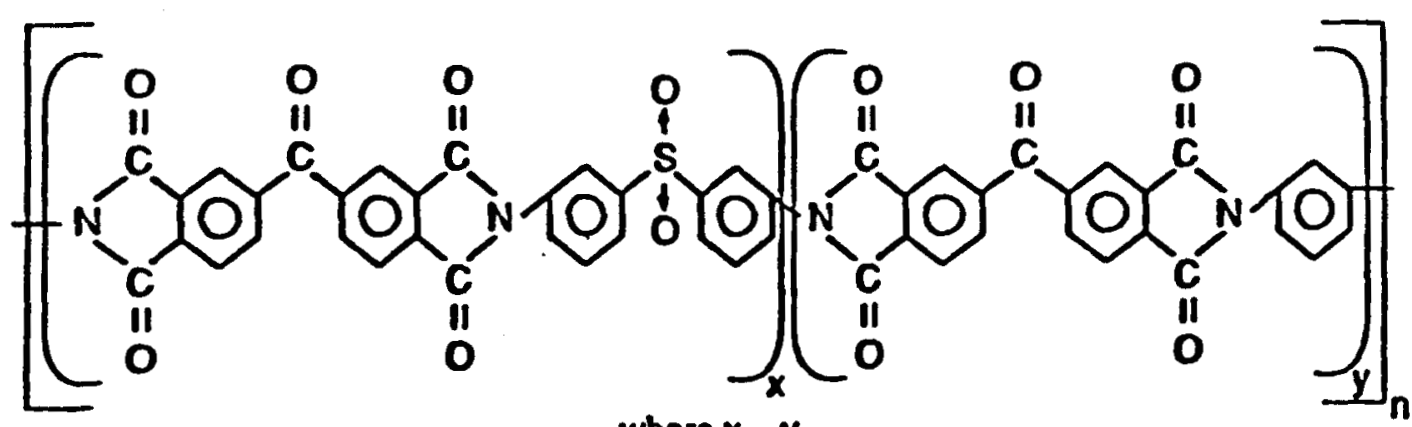

where $x=y$

LARC-F-SO

EXPERIMENTAL

Materials and polymer synthesis

The experimental procedures for the synthesis of the polyimides, except for $\mathrm{LARC}-\mathrm{F}-\mathrm{SO}_{2}$ and endcapped $\mathrm{PISO}_{2}$, have been reported previously. The procedure for the synthesis of $\mathrm{LARC}-\mathrm{F}-\mathrm{SO}_{2}$ involved the use of reagent grade monomers and solvents that are commercially available. The list of chemicals, abbreviations, their source and m.p. or b.p. follows: benzophenonetetracarboxylic acid dianhydride (BTDA), Allco Company, Pittsburg, KA, m.p. $224-226^{\circ} \mathrm{C}$; meta-phenylenediamine (MPD), purissimus grade from Fluka Chemical Company, Hauppauge, NY, m.P. $61-63^{\circ} \mathrm{C} ; 3,3^{\prime}-$ diaminodiphenylsulfone $\left(3,3^{\prime}-\mathrm{DDSO}_{2}\right)$, FIC Corporation, San Francisco, CA, m.p. $165-167^{\circ} \mathrm{C}$; bis-2-methoxyethylether (diglyme), Fluka Chemical Company, b.p. $60-62^{\circ} \mathrm{C}$; N,N-dimethylacetamide (DMAC), Fluka Chemical Company, b.p. $165-167^{\circ} \mathrm{C}$.

The preparation of the polymers was carried out at room temperature in a $1000 \mathrm{ml}$ cylindrical flask with a removable, four-neck top. Stirring of the mixture was accomplished using an impeller blade driven by a constant-torque, overhead motor equipped with a variable speed control. 
The BTDA (16.273 $\mathrm{g}, 0.505 \mathrm{M})$ was slurried in $135 \mathrm{~g}$ of diglyme at ambient temperature $\left(-20^{\circ} \mathrm{C}\right)$. Next the $3,3^{\prime}-\mathrm{DDSO}_{2}(6.20 \mathrm{~g}, 0.0250 \mathrm{M})$ was added and the mixture was allowed to stir for approximately one hour. At this point the materials were all in solution as the $3,3^{\prime}-\mathrm{DDSO}_{2}$ and the BTDA had reacted as evidenced by a slight increase in temperature. The MPD $(2.704 \mathrm{~g}, 0.0250 \mathrm{M})$ was added to the reaction vessel, the polymerization reaction continued rapidly and a precipitation of the polyamide-acid copolymer occurred within $15 \mathrm{~min}$. In order to redissolve the polymer, $55 \mathrm{~g}$ of DMAc was added and stirring continued overnight. The polymer redissolved and was used as a $11.6 \mathrm{wt} \%$ solid solution to prepare the adhesive scrim cloth and for priming. The inherent viscosity $\left(\eta_{i n h}\right)$ of the polymer, as determined at $0.5 \mathrm{wt} \%$ solids in DMAC at $35^{\circ} \mathrm{C}$, was $0.724 \mathrm{dl} / \mathrm{g}$.

The monomers used in the preparation of endcapped $\mathrm{PISO}_{2}$ were $\mathrm{BTnA}$, $3,3^{\prime}-\mathrm{DDSO}_{2}$, and phthalic anhydride (PA) obtained from Eastman Kodak Company, Rochester, NY, m.p. $131^{\circ} \mathrm{C} \mathrm{w/3}{ }^{\circ} \mathrm{C}$ range. The polymer was prepared as a 20 wt\% solids solution in a mixed solvent of diglyme and tetrahydrofuran (THF). The THF was obtained from Aldrich Chemical Company, Inc., Milwaukee, Wisconsin, Gold label (99.9\%), b.p. $67^{\circ} \mathrm{C}$.

The BTDA $(193.2 \mathrm{~g}, 0.6 \mathrm{M})$ and $3,3^{\prime}-\mathrm{DDSO}_{2}(148.8 \mathrm{~g}, 0.6 \mathrm{M})$ were dissolved at ambient conditions in the digiyme/THF (1410 g/90 g) mixed solvent and stirred for 16 hours. Most of the solids, approximately 90 percent, dissolved initially with the rest of the BTDA dissolving over the remaining reaction time. The solution was amber-orange in color. The PA $(1.2 \mathrm{~g}, 0.008 \mathrm{M})$ was dissolved in $8 \mathrm{ml}$ of DMAC and added to the polyamic-acid solution. Some precipitation occurred initially but 
cleared up within one minute. The inherent viscosity was determined to be $0.589 \mathrm{dl} / \mathrm{g}$.

Characterization

Lap shear strength (LSS) was obtained according to ASTM D-1002 using a Model TT Instron Universal Testing Machine. The LSSs reported represent an average of four lap shear specimens per test condition except as noted in the tables. The range of LSSs is indicated by dashed lines in the bar graph figures and is listed in the tables. Elevated temperature tests were conducted in a clam-shell, quartz-lamp oven with temperatures controlled to within $\pm 3^{\circ} \mathrm{C}$ for all tests. Specimens were held $10 \mathrm{~min}$ at temperature prior to testing except for the water-boil test specimens for which the tests were conducted as soon as the test temperature was reached (approximately 1-2 $\mathrm{min}$ ).

Bondline thickness is defined as the difference between the total joint thickness measured with a micrometer and the sum of the adherend thicknesses. The average bondline thickness for the thermally aged and water-boil specimens was $0.025 \mathrm{~cm}$ for $\mathrm{PISO}_{2}, 0.015 \mathrm{~cm}$ for $\mathrm{LARC}_{-} \mathrm{F}-\mathrm{SO}_{2}$, $0.009 \mathrm{~cm}$ for LARC-TPI, and $0.017 \mathrm{~cm}$ for LARC-STPI.

Glass transition temperatures $(\mathrm{Tg})$ of the adhesive from the fractured lap shear specimens were determined by thermomechanical analysis (TMA) on a DuPont 943 Analyzer.* TMAs were run on the fractured

* Use of trade names or company names does not constitute an official endorsement by NASA, either expressed or implied. 
lap shear specimens in static air at a heating rate of $5^{\circ} \mathrm{C} / \mathrm{min}$ using a hemispherical probe with a $15 \mathrm{~g}$. load.

Thermomechanical spectra of the polymers were obtained on a torsional braid analysis (TBA) system interfaced with an IBM PC. Individual glass braids were coated with a 11.6 wt\% solids $L A R C-F-S_{2}$ polyamic acid solution and a 5 wt\% solids $\mathrm{PISO}_{2}$ solution and precured in air for one hour at each of three temperatures: $100^{\circ} \mathrm{C}, 200^{\circ} \mathrm{C}$ and $300^{\circ} \mathrm{C}$. Tests were conducted by heating in a nitrogen atmosphere to $400^{\circ} \mathrm{C}$ at $3{ }^{\circ} \mathrm{C} / \mathrm{min}$. $\mathrm{Tg}$ was determined as the extrapolated maximum peak height of the damping versus temperature curve.

Inherent viscosity was determined using a Cannon-Ubbelohde viscometer in a $35^{\circ} \mathrm{C}$ water bath controlled to within $\pm 0.01^{\circ} \mathrm{C}$. A $10 \mathrm{ml}$ solution of $0.5 \mathrm{wt} \%$ solids in $\mathrm{N}, \mathrm{N}$-dimethylacetamide (DMAC) was made and filtered. The average of three runs of the solution was reported.

Adhesive tape preparation

Adhesive tape for the $\mathrm{PISO}_{2}$ was prepared by brush coating a primer solution of polyamic-acid, diluted to approximately 5 wt\% solids in diglyme/THF, onto 112 E-glass cloth with A-1100 finish ( $Y$-aminopropylsilane). The glass cloth had been tightly mounted on a metal frame and dried in a forced-air oven for $30 \mathrm{~min}$ at $100^{\circ} \mathrm{C}$ prior to coating. The $0.01 \mathrm{~cm}$ thick glass cloth served as a carrier for the adhesive as well as for bondline control and an escape channel for solvent. The coated cloth was then air-dried for $1 \mathrm{hr}$ at ambient temperature and heated for $1 \mathrm{hr}$ at each of three temperatures: $100^{\circ} \mathrm{C}, 150^{\circ} \mathrm{C}$ and $175^{\circ} \mathrm{C}$. Subsequently, each 
application of a 20 wt\% solids solution, $n_{i n h} 0.589 \mathrm{dl} / g$, was brush coated onto the cloth and exposed to the following schedule until a thickness of $0.025-0.027 \mathrm{~cm}$ was obtained:

(1) Room temperature (RT), held $1 \mathrm{hr}$

(2) $\mathrm{RT}+100^{\circ} \mathrm{C}$, held $1 \mathrm{hr}$

(3) $100^{\circ} \mathrm{C}+150^{\circ} \mathrm{C}$, held $1 \mathrm{hr}$

(4) $150^{\circ} \mathrm{C}+175^{\circ} \mathrm{C}$, held $1 \mathrm{hr}$

Adhesive tape for LARC- $-\mathrm{SO}_{2}$ was prepared in a similar manner in an attempt to standardize the tape preparations. An approximatley 5 wt\% solids solution of polyamic-acid in diglyme/DMAc was used to prime coat the oven-dried glass cloth. The prime coated cloth was air-dried for 1 $\mathrm{hr}$ at ambient temperature and heated for $1 \mathrm{hr}$ at each of three temperatures: $100^{\circ} \mathrm{C}, 150^{\circ} \mathrm{C}$ and $175^{\circ} \mathrm{C}$. Subsequently, after each application of an 11.6 wt\% solids solution onto the cloth, the tape was exposed to the following schedule until a thickness of $0.018-0.023 \mathrm{~cm}$ was obtained:

(1) RT, held $1 \mathrm{hr}$

(2) $\mathrm{RT}+100^{\circ} \mathrm{C}$, held $1 \mathrm{hr}$

(3) $100^{\circ} \mathrm{C} \cdot 150^{\circ} \mathrm{C}$, held $2 \mathrm{hrs}$

(4) $150^{\circ} \mathrm{C}+175^{\circ} \mathrm{C}$, held $3 \mathrm{hrs}$

The involved procedure to prepare the tapes was necessary to drive-off solvent and reaction product volatiles when converting the polyamic-acid resin to the polyimide. Imidization of polyamic-acids to polyimides generally occurs above $160^{\circ} \mathrm{C}$ with the degree of conversion being a function of time and temperature. 
Adhesive bonding

The prepared adhesive tapes were used to bond titanium alloy adherends (Ti-6Al-4V, per Mil-T-9046E, Type III Comp. C) with a nominal thickness of $0.13 \mathrm{~cm}$. The $\mathrm{Ti}-6 \mathrm{Al}-4 \mathrm{~V}$ panels were grit blasted with 120 grit aluminum oxide, washed with methanol, and treated with Pasa Jell 107* to form a stable oxide on the surface. The adherends were washed with water and dried in a forced-air oven at $100^{\circ} \mathrm{C}$ for $5 \mathrm{~min}$. The treated adherends were primed within two hours of the surface treatment by applying a thin coat of the polyamic-acid solution of the respective adhesive on the surfaces to be bonded. After air drying in a forced-air oven for $30 \mathrm{~min}$, they were heated for $15 \mathrm{~min}$ at $100^{\circ} \mathrm{C}$ and $15 \mathrm{~min}$ at $150^{\circ} \mathrm{C}$. The primed adherends were placed in a polyethylene bag and stored in a desiccator until needed. Lap shear specimens were prepared by inserting the adhesive tape between the primed adherends using a $1.27 \mathrm{~cm}$ overlap (ASTM D-1002) and applying 2.07 MPa pressure in a hydraulic press during the heating schedule. Bonding temperature was monitored using a type $k$ thermocouple spot-welded to the titanium adherend at the edge of the bondline.

Several bonding cycles for the $L A R C-F-S_{2}$ adhesive were investigated during this study to determine a bonding process which produced good strengths. The cycle selected was as follows:

*Trade name for a titanium surface treatment available from Semco, Glendale, CA. 
(1) $2.07 \mathrm{MPa}$ pressure, heating rate $\approx 8.2^{\circ} \mathrm{C} / \mathrm{min}, \mathrm{RT}+343^{\circ} \mathrm{C}$

(2) Held $1 \mathrm{hr}$ at $343^{\circ} \mathrm{C}$

(3) Cool under pressure to $\approx 150^{\circ} \mathrm{C}$ and remove from bonding press

Past experience with these types of thermoplastic polyimides had shown a beneficial affect when heating the adhesive tape to higher temperatures for a period of time. ${ }^{9}$ The adhesive tape heat treatment selected was that which gave the best lap shear strengths and involved an additional heat treatment of $1 \mathrm{hr}$ each at $200^{\circ} \mathrm{C}, 225^{\circ} \mathrm{C}$ and $250^{\circ} \mathrm{C}$. The color of the tape changed from a straw yellow to amber. The heat treated LARC-F $-\mathrm{SO}_{2}$ adhesive tape which was stiff and boardy was used to prepare lap shear specimens for thermal exposure and water boil tests. LSS tests were conducted at $\mathrm{RT}, 177^{\circ} \mathrm{C}$ and $204^{\circ} \mathrm{C}$.

A similar procedure was used to determine the best heat treatment for the $\mathrm{PISO}_{2}$ adhesive tape. The same bonding cycle that was used for LARC-F-SO $-\mathrm{SO}_{2}$ was used for $\mathrm{PISO}_{2}$. The heat treatment chosen for the $\mathrm{PISO}_{2}$ included additional heating for $1 \mathrm{hr}$ at each temperature from $200^{\circ} \mathrm{C}$ to $275^{\circ} \mathrm{C}$ in $25^{\circ} \mathrm{C}$ increments. Some foaming of the tape resulted due to the heat treatment and the adhesive was stiff and boardy with no tack or drape. Specimens were prepared with this tape for thermal exposure and water boil.

Thermal exposures at $204^{\circ} \mathrm{C}$ for $500 \mathrm{hrs}$ and $1000 \mathrm{hrs}$ were performed in a forced-air oven controlled within $\pm 2^{\circ} \mathrm{C}$. Lap shear tests were conducted at $\mathrm{RT}, 177^{\circ} \mathrm{C}$ and $204^{\circ} \mathrm{C}$ before (controls) and after thermal exposure.

In order to determine the effects of humidity (moisture) on an adhesive, a 72-hr water boil was conducted in laboratory glassware 
containing distilled boiling water. The bonded area of the lap shear specimens was immersed during a 72-hr period. LSSS were subsequently determined at $\mathrm{RT}, 177^{\circ} \mathrm{C}$ and $204^{\circ} \mathrm{C}$.

These two adhesive systems, LARC-F-SO 2 and $\mathrm{PSIO}_{2}$ were compared with results previously reported for LARC-TPI and LARC-STPI. ${ }^{10}$

RESULTS AND DISCUSSION

Resin chemistry

The proposed general reaction scheme for the formation of the polyimide polymers to be evaluated is shown in Figure 1. A discussion of the reactions to form $L A R C-F-S_{2}$ and $\mathrm{PISO}_{2}$, in this case a $P A$ endcapped version, is given since the reaction scheme of LARC-TPI and the random copolymer, LARC-STPI, is reported in the literature. ${ }^{5}, 10$

The structure of $L A R C-F-S_{2}$ formed from the monomer BTDA, $3,3^{\prime}-\mathrm{DnSO}_{2}$ and MPD is shown in Figure 2. The copolymer contains bridged, aromatic diamines with meta catenation. Meta-oriented diamines were shown to have improved processability and improved adhesive strength when compared to para-oriented diamines. ${ }^{7}$ The meta linkages, as in both amine-derived moieties, should introduce thermoplasticity because of the inherent flexibility of these units of the polymer chain. The use of mixed solvents, as in the preparation of $L A R C-F-S_{2}$, is not preferred. Data from our laboratory has shown that the use of diglyme is preferred over amide solvents such as DMAC. ${ }^{4}$ However, in the present study the use of a mixed solvent system was necessitated by the insolubility of the 
polyamic acid of LARC-F-SO 2 in diglyme. We feel that the ultimate adhesive properties of this copolymer are lower than would be expected if only diglyme were the solvent. Some of the darkening of the adhesive during bonding might be attributable to the presence of DMAC since this phenomenon was noted in adhesives reported in reference 4.

The structure of $\mathrm{PISO}_{2}$ formed from $\mathrm{BTDA}$ and $3,3^{\prime}-\mathrm{DDSO}_{2}$ with $\mathrm{PA}$ end caps is shown in Figure 2. The formation of $\mathrm{PISO}_{2}$ without end capping had been discussed in references 7 and 9. The purpose of endcapping this polymer was to control the molecular weight of the polymer chains allowing greater flow during processing and to prevent chain extension during cure which creates volatiles and foaming. Again, the metaoriented diamine, $3,3^{\prime}-\mathrm{DDSO}_{2}$, allows flexibility in the polymer chain and is partially responsible for some of the thermoplasticity of the polymer. Also shown in Figure 2 are the structures of LARC-TPI and LARC-STPI.

LSS and durability comparison

Test results from this study for $\mathrm{LARC}-\mathrm{F}-\mathrm{SO}_{2}$ and $\mathrm{PISO}_{2}$ are compared with data reported for $\mathrm{PISO}_{2}$ in Table I and Figure 3. Figure 3 shows the LSSs for non-exposed specimens for tests conducted at RT, $177^{\circ} \mathrm{C}, 204^{\circ} \mathrm{C}$ and $232^{\circ} \mathrm{C}$ where Table 1 includes processing information and thermal aging data. LARC-F-SO $\mathrm{SO}_{2}$ and $\mathrm{PISO}_{2}$ each have $\mathrm{BTDA}$ and the diamine, $3,3^{\prime}-\mathrm{DDSO}_{2}$, in common. The strength test results of the present study indicate the $\mathrm{PISO}_{2}$ adhesive system provides significantly higher strengths at RT, $177^{\circ} \mathrm{C}$ and $204^{\circ} \mathrm{C}$ than the LARC-F-SO 2 adhesive system: RT, $27.5 \mathrm{MPa}$ compared to $17.9 \mathrm{MPa} ; 177^{\circ} \mathrm{C}, 27.5 \mathrm{MPa}$ compared to $18.8 \mathrm{MPa}$; and $204^{\circ} \mathrm{C}$, 
20.4 MPa compared to $19.6 \mathrm{MPa}$. $\mathrm{PISO}_{2}$ also had a LSS of $23.1 \mathrm{MPa}$ at $232^{\circ} \mathrm{C}$. Slight differences in the bonding process, the adhesive resin, the preparation of the adhesive tape, and surface treatment may account for the small differences in the strength values for $\mathrm{PISO}_{2}$ reported in references 7 and 9, although they are still comparable to those of the present study. Note the good strengths retained for those thermally aged up to $5000 \mathrm{hrs}$ at $204^{\circ} \mathrm{C}$ in reference 7 , i.e. $20.5 \mathrm{MPa}$ for RT and $204^{\circ} \mathrm{C}$ tests.

Figure 4 and Table II present the results of thermal exposure in air at $204^{\circ} \mathrm{C}$ for $\mathrm{LARC}-\mathrm{F}-\mathrm{SO}_{2}$ and $\mathrm{PISO}_{2}$ (present study). Results are expressed in graphical form for those interested in obtaining a quick pictorial summary of the results and in tabular form for those interested in more detail and additional information not included in the graphs such as $\mathrm{Tg}$, failure mode, and the number of specimens tested. No change in LSS at RT, $177^{\circ} \mathrm{C}$ and $204^{\circ} \mathrm{C}$ was observed for LARC-F-SO 2 thermally aged for up to $1000 \mathrm{hrs}$. A slight increase in strength with test temperature was indicated although the range of strengths tend to overlap in most cases. Failures were primarily conesive except for the RT tests for the $500 \mathrm{hrs}$ and $1000 \mathrm{hrs}$ exposure which were primarily adhesive failure. The darkening of the adhesive in the fractured area (almost black) is typical of systems which use the amide solvents. A significant increase in Tg, $16^{\circ} \mathrm{C}$, was determined after the $1000 \mathrm{hr}$ exposure. This increase is not unusual for polyimides and has been noticed in past studies. Tg, measured by the TBA technique, of LARC-F- $-\mathrm{SO}_{2}$ pretreated for $1 \mathrm{hr}$ each at $100^{\circ} \mathrm{C}, 200^{\circ} \mathrm{C}$ and $300^{\circ} \mathrm{C}$ was $282^{\circ} \mathrm{C}$ compared to the $\mathrm{Tg}$ determined by TMA (penetration technique) in the fractured area, $255^{\circ} \mathrm{C}$. 
A slight decrease in LSS was found for $\mathrm{PISO}_{2}$ specimens exposed for $500 \mathrm{hrs}$ and $1000 \mathrm{hrs}$ at $204^{\circ} \mathrm{C}$. Those exposed for $1000 \mathrm{hrs}$ were $90 \%$ of the control's value at RT, $80 \%$ at $177^{\circ} \mathrm{C}, 87 \%$ at $204^{\circ} \mathrm{C}$ and $86 \%$ at $232^{\circ} \mathrm{C}$. Joint failures were primarily cohesive for all tests except for the RT control test which was cohesive/adhesive. The color of the adhesive in the failed bond area was almost black. A slight general increase in $\mathrm{Tg}$ with increasing time of thermal exposure was observed, increasing from an average $256^{\circ} \mathrm{C}$ for the controls to $268^{\circ} \mathrm{C}$ for those exposed for $1000 \mathrm{hrs}$. As with LARC-F- $-\mathrm{SO}_{2}$, this phenomenon is typical of polyimides. The Tg determined by TBA for $\mathrm{PISO}_{2}$ pretreated for $1 \mathrm{hr}$ each at $100^{\circ} \mathrm{C}, 200^{\circ} \mathrm{C}$ and $300^{\circ} \mathrm{C}$ was $272^{\circ} \mathrm{C}$.

Results of thermal exposure in air at $204^{\circ} \mathrm{C}$ for LARC-TPI and LARC-STPI are given in Figure 5 and Table III. Data are shown for LSS tests conducted at RT, $177^{\circ} \mathrm{C}$ and $204^{\circ} \mathrm{C}$ after thermal exposures of $500 \mathrm{hrs}$ and 1000 hrs.

LARC-TPI provides excellent strength for all three test temperatures with no change in strength due to the thermal exposure. Previous work reported has shown the polymer to have excellent thermooxidative resistance. ${ }^{5}$ There is a general decrease in strength with increasing test temperature; however, the decrease is sma11: less than $24 \%$ for the worst case, 1.e. $33.0 \mathrm{MPa}$ to $25.2 \mathrm{MPa}$. All failures were $100 \%$ cohesive. Tgs ranged from $225^{\circ} \mathrm{C}$ to $246^{\circ} \mathrm{C}$. The $\mathrm{Tg}$ of a fflm treated for $1 \mathrm{hr}$ each at $100^{\circ} \mathrm{C}, 200^{\circ} \mathrm{C}$ and $300^{\circ} \mathrm{C}$ determined by DSC, was $260^{\circ} \mathrm{C} .{ }^{10}$

The copolymer, LARC-STPI, which has the meta-linked phenylenediamine structure in common with LARC-F-SO with thermal exposure. The strengths of those exposed for $500 \mathrm{hrs}$ and 
$1000 \mathrm{hrs}$, approximately $23 \mathrm{MPa}$, are the same, but slightly lower than the control's strengths, approximately $26 \mathrm{MPa}$. The primary failure mode was cohesive except for the 500 and $1000 \mathrm{hr}$ exposure specimens tested at RT which were cohesive/adhesive and adhesive, respectively. The Tgs determined for LARC-STPI fractured specimens were between $260^{\circ} \mathrm{C}$ and $267^{\circ} \mathrm{C}$. A Tg of $283^{\circ} \mathrm{C}$, determined by TBA, was reported earlier for LARC-STPI pretreated for $1 \mathrm{hr}$ each at $100^{\circ} \mathrm{C}, 200^{\circ} \mathrm{C}$ and $300^{\circ} \mathrm{C}$.

An overall comparison of the four adhesive systems shows LARC-TPI to provide the highest LSSs, approximately $33 \mathrm{MPa}$ at $\mathrm{RT}, 30 \mathrm{MPa}$ at $177^{\circ} \mathrm{C}$ and $26 \mathrm{MPa}$ at $204^{\circ} \mathrm{C}$. LARC-F-SO $\mathrm{S}_{2}$, LARC-TPI and LARC-STPI all retain their strengths after thermal exposure up to $1000 \mathrm{hrs}$ at $204^{\circ} \mathrm{C}$ and $\mathrm{PISO}_{2}$ retains greater than $80 \%$ of the control's strength at each test temperature after exposure. LARC-TPI had the lowest range of Tgs, $228^{\circ} \mathrm{C}$ to $246^{\circ} \mathrm{C}$, of the four adhesives. All the others ranged from $251^{\circ} \mathrm{C}$ to $273^{\circ} \mathrm{C}$. The predominant failure mode was cohesive.

72-Hour water boil

The resistance of the four adhesive systems to water (humidity) was determined by immersing lap shear specimens in distilled boiling water for a $72-h r$ period and subsequently testing their LSS at RT, $177^{\circ} \mathrm{C}$ and $204^{\circ} \mathrm{C}$. Results of the present study for $L A R C-F-S_{2}$ and $\mathrm{PISO}_{2}$ are given along with results reported for LARC-TPI and LARC-STPI ${ }^{10}$ in Figure 6 and Table IV.

LARC $-\mathrm{F}-\mathrm{SO}_{2}$ which has the lowest control strengths of the four adhesive systems for all three test temperatures shows a slight increase 
in strengths at RT and $177^{\circ} \mathrm{C}(112 \%$ and $102 \%$ of the controls values, respectively). However, at $204^{\circ} \mathrm{C}$ the strength was $80 \%$ of the control's strength. This percentage retention was excellent when compared to other polyimide systems including those reported here. The primary failure mode after water boil was cohesive whereas the control's failures were a combination of cohesive/adhesive at RT and $177^{\circ} \mathrm{C}$. There was essentially no change in $\mathrm{Tg}$ due to the water boil.

A decrease in LSS with increasing test temperature was determined for the $\mathrm{PISO}_{2}$ system. The LSS values after water boil were $79 \%$ of the control's RT strength, $68 \%$ for the $177^{\circ} \mathrm{C}$ test, and $61 \%$ for the $204^{\circ} \mathrm{C}$ test. The control strengths for $\mathrm{PISO}_{2}$ were significantly higher than those for $L A R C-F-S_{2}$; therefore, even though the percent of strength retention was lower for $\mathrm{PISO}_{2}$, the absolute LSS values after water boil were still about the same as those for LARC-F-SO 2 . Specimens examined after the water boil tests were found to be primarily cohesive failures as were those of the controls. No significant change in $\mathrm{Tg}$ was noted after the water boil tests.

LARC-TPI initially provided the highest control LSSs at RT and $177^{\circ} \mathrm{C}$ of the four adhesive systems and about the same strength at $204^{\circ} \mathrm{C}$ as $\mathrm{PISO}_{2}$ and LARC-STPI (24 to $25 \mathrm{MPa}$ ). After water boil, LARC-TPI retained $84 \%$ of the control's RT strength, $67 \%$ of the control's $177^{\circ} \mathrm{C}$ strength, and only $40 \%$ of the control's $204^{\circ} \mathrm{C}$ strength, the poorest percent retention and the lowest strength value, $10.1 \mathrm{MPa}$, of the four adhesives tested. Failures were all primarily cohesive before and after water boil. No significant changes in $\mathrm{Tg}$ were found. 
Water boil also produced reduced strengths for LARC-STPI. The LSSs of LARC-STPI specimens tested after water boil were $88 \%$ of the control's RT strength, $62 \%$ of the control's $177^{\circ} \mathrm{C}$ strength and $68 \%$ of the control's $204^{\circ} \mathrm{C}$ strength. LARC-STPI had the highest strength at $204^{\circ} \mathrm{C}$ of the four adhesive systems, an average of $17.0 \mathrm{MPa}$; slightly higher than LARC-F$\mathrm{SO}_{2}, 15.7 \mathrm{MPa}$ and $\mathrm{PISO}_{2}, 14.7 \mathrm{MPa}$ and significantly higher than LARC-TPI, 10.1 MPa. The failure mode for the tested LARC-STPI was primarily cohesive. No change in $\mathrm{Tg}$ was determined after water boil.

\section{SUMMARY}

Research continues at Langley Research Center on synthesis and development of new inexpensive flexible aromatic polyimides as adhesives which contain bridged aromatic diamines with meta cantenation. The present work resulted in a material identified as LARC-F- $\mathrm{SO}_{2}$ with similarities to polyimidesulfone, $\mathrm{PISO}_{2}$, and other flexible backbone polyimides recently reported by Progar and St. Clair. Also prepared in our laboratory and evaluated was a phthalic anhydride endcapped version of $\mathrm{PISO}_{2}$. These two polymers were synthesized and evaluated as adhesives and compared with LARC-TPI and LARC-STPI, polyimides researched in our laboratory and reported in literature.

The adhesive evaluation, primarily based on lap shear strength (LSS) tests, involved preparing adhesive tapes, conducting bonding studies, and exposing lap shear specimens to a thermal exposure in air at $204^{\circ} \mathrm{C}$ for up to 1000 hrs and a 72-hr water boil exposure. LSS tests at RT, $177^{\circ} \mathrm{C}$ and $204^{\circ} \mathrm{C}$ were performed before (controls) and after these exposures. The 
type of adhesive failure as well as the glass transition temperature, Tg, was determined for the fractured specimens.

When comparing all four adhesive systems, the results indicate that LARC-TPI provides the highest LSSs, $33 \mathrm{MPa}$ at RT, $30 \mathrm{MPa}$ at $177^{\circ} \mathrm{C}$ and 26 $\mathrm{MPa}$ at $204^{\circ} \mathrm{C}$. LARC-F-SO2, LARC-TPI and LARC-STPI all retain their strengths after thermal exposure at $204^{\circ} \mathrm{C}$ in air for up to $1000 \mathrm{hrs}$, the maximum time considered in this study and $\mathrm{PISO}_{2}$ retains greater than $80 \%$ of its control strengths. The predominant failure mode was cohesive.

After a 72-hr water boil exposure, most of the four adhesive systems showed reduced strengths for all elevated test temperatures. All adhesive systems exhibited a high percentage of strength retention for the three test temperatures (> 60\%) except for LARC-TPI tested at $204^{\circ} \mathrm{C}$ which had a $40 \%$ retention. LARC-STPI retained the highest strength at $204^{\circ} \mathrm{C}$, approximately $17.0 \mathrm{MPa}$; slightly higher than LARC-F-SO $\mathrm{S}_{2}, 15.7 \mathrm{MPa}$ and $\mathrm{PISO}_{2}, 14.7 \mathrm{MPa}$; and significantly higher than LARC-TPI, 10.1 MPa. Failure modes were primarily cohesive for all adhesive systems. No significant changes in Tgs were found.

Although the LARC-F-SO $\mathrm{S}_{2}$ could not be prepared in diglylme alone as the solvent, the properties of the resulting adhesive were notable. The darkening of the adhesive during bonding was typical of systems which utilize amide solvents.

\section{References}

1. V. L. Bell, B. L. Stump and H. Gager, J. Polym. Sci.: Polym. Chem. Ed. 14, 2275 (1976). 
2. V. L. Bell, "Process for Preparing Thermoplastic Aromatic Polyimides," U.S. Patent 4.094862 (1968).

3. D. J. Progar, V. L. Bell and T. L. St. Clair, "Polyimide Adhesives," U.S. Patent 4065345 (Dec. 1977).

4. T. L. St. Clair and D. J. Progar, "Solvent and Structure Studies of Novel Polyimide Adhesives," Adhesive Sci. and Tech., Plenum Press, New York, 9A, 187 (1975).

5. A. K. St. Clair and T. L. St. Clair, "A Multipurpose Thermoplastic Polyimide, 26th Nat. SAMPE Symp., 26, 165 (1981).

6. D. J. Progar and T. L. St. Clair, "Flexibilized Copolyimide Adhesives," J. Adhesion, 21, 35 (1987).

7. T. L. St. Clair and D. A. Yamaki, "A Thermoplastic Polyimidesulfone," NASA TM-84574 (1984).

8. T. L. St. Clair and D. J. Progar, "Adhesive Evaluation of New Polyimides," Proc. Fifth International Joint Military/GovernmentIndustry Symp. on Structural Adhesive Bonding, 37 (Nov. 1987).

9. D. J. Progar, "Processing Study of a High Temperature Adhesive," Int. J. of Adhesion and Adhesives, 4, no. 2, 79 (April 1984).

10. D. J. Progar and T. L. St. Clair, "A Thermoplastic Copolyimide," 2nd Int. Conf. on Polyimides, in SPE Proceedings, Recent Advances in Polyimide Sci. and Tech., 139 (1987) or NASA TM-86447 (July 1985). 

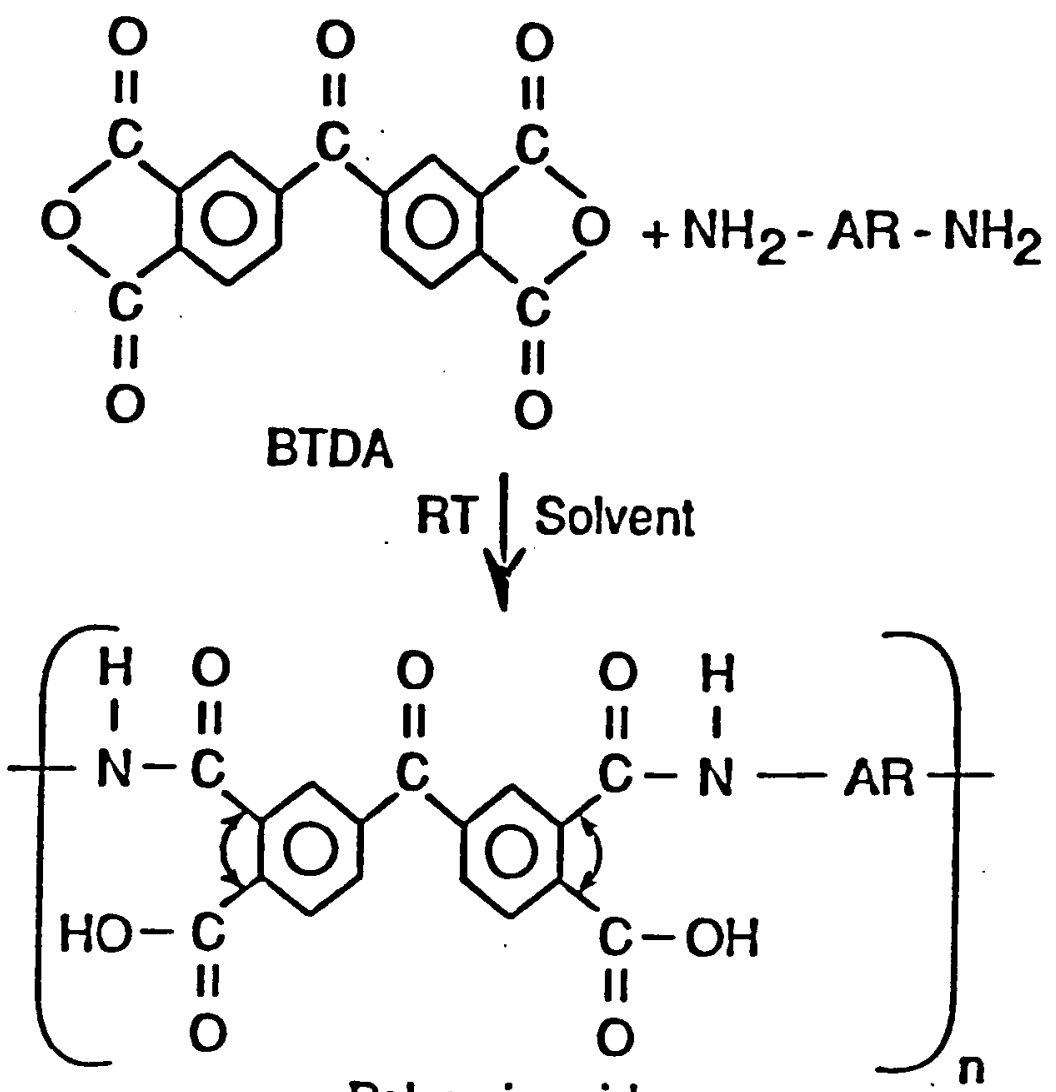

Polyamic acid
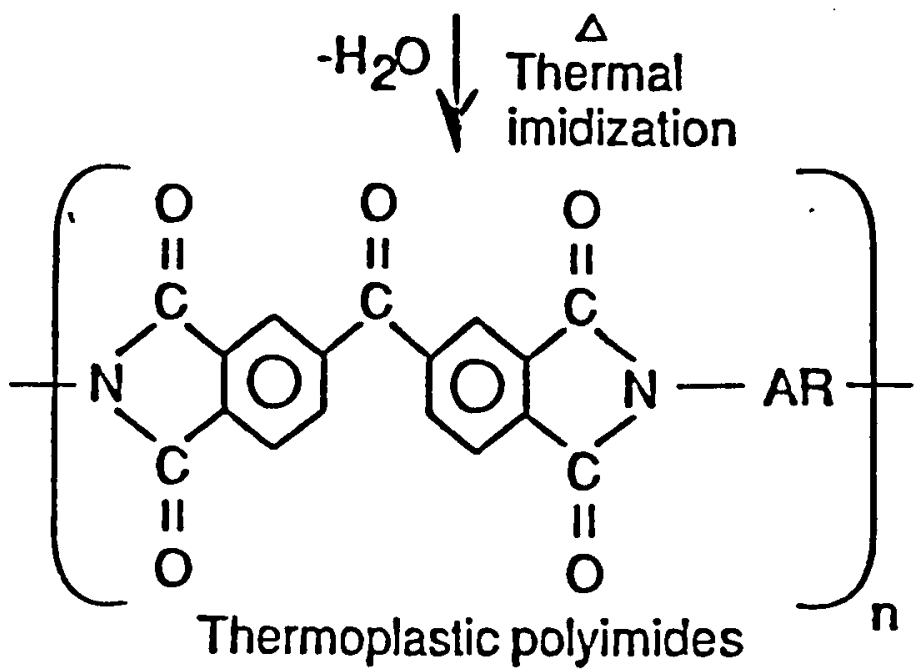

Figure 1. General reaction scheme. 
$[\underbrace{(I)}_{0}$

LARC-F-SO 2<smiles>CCCCN1C(=O)c2ccc(C(=O)c3ccc4c(c3)C(=O)N(c3cccc([SH](=O)(O)c5cccc(S(O)(O)c6cccc(S(O)(O)c7cccc(C)c7)c6)c5)c3)C4=O)cc2C1=O</smiles>

$\mathrm{PISO}_{2}$

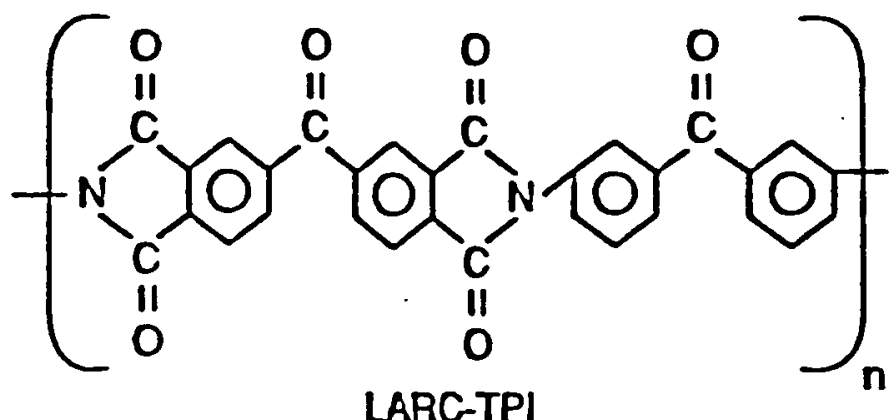

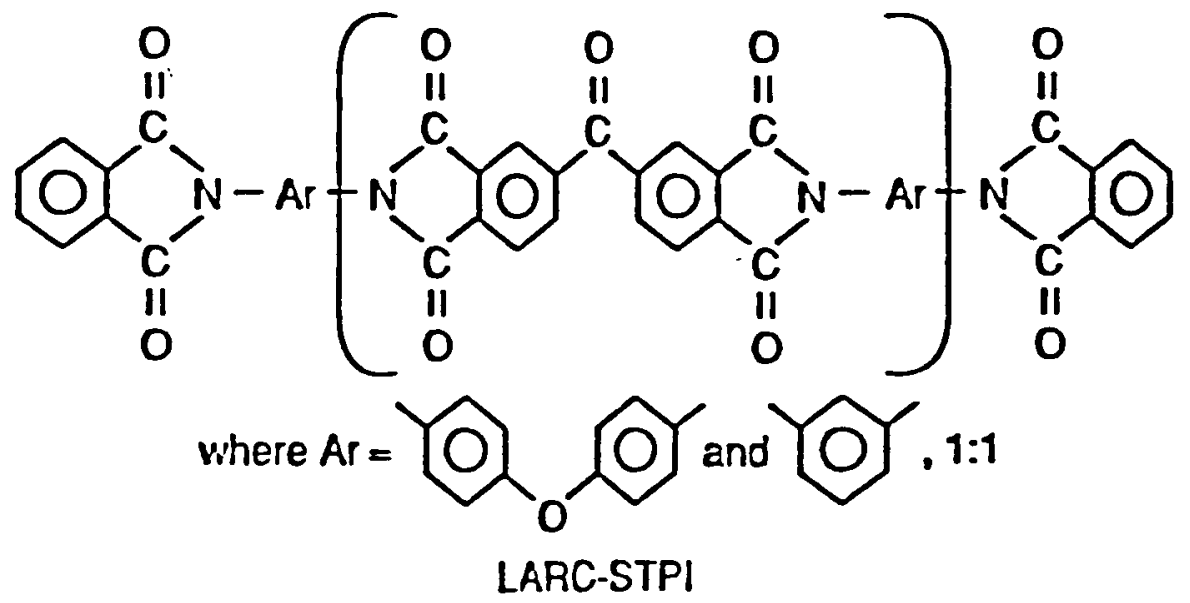

Figure 2. Thermoplastic polyimide structures. 


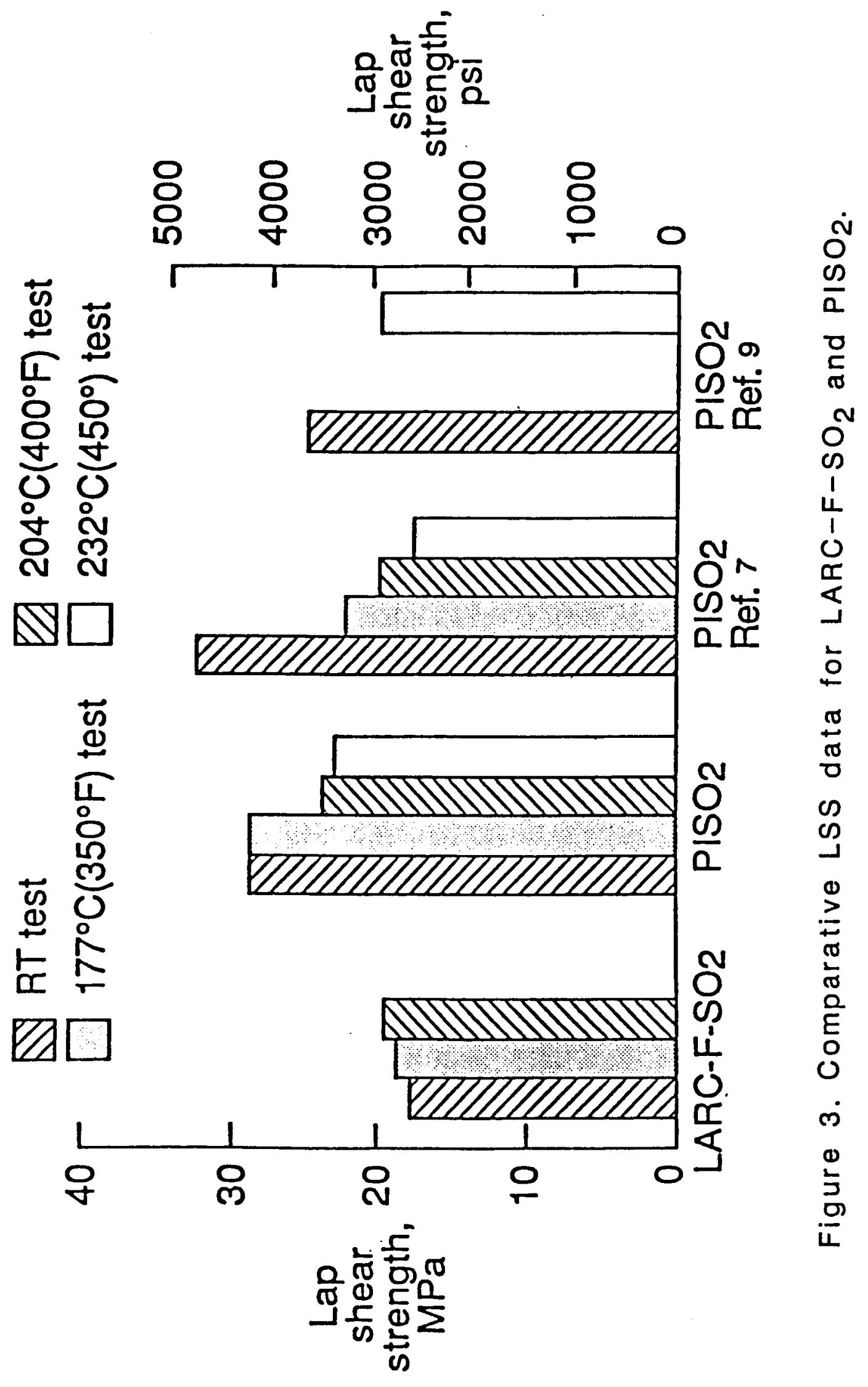




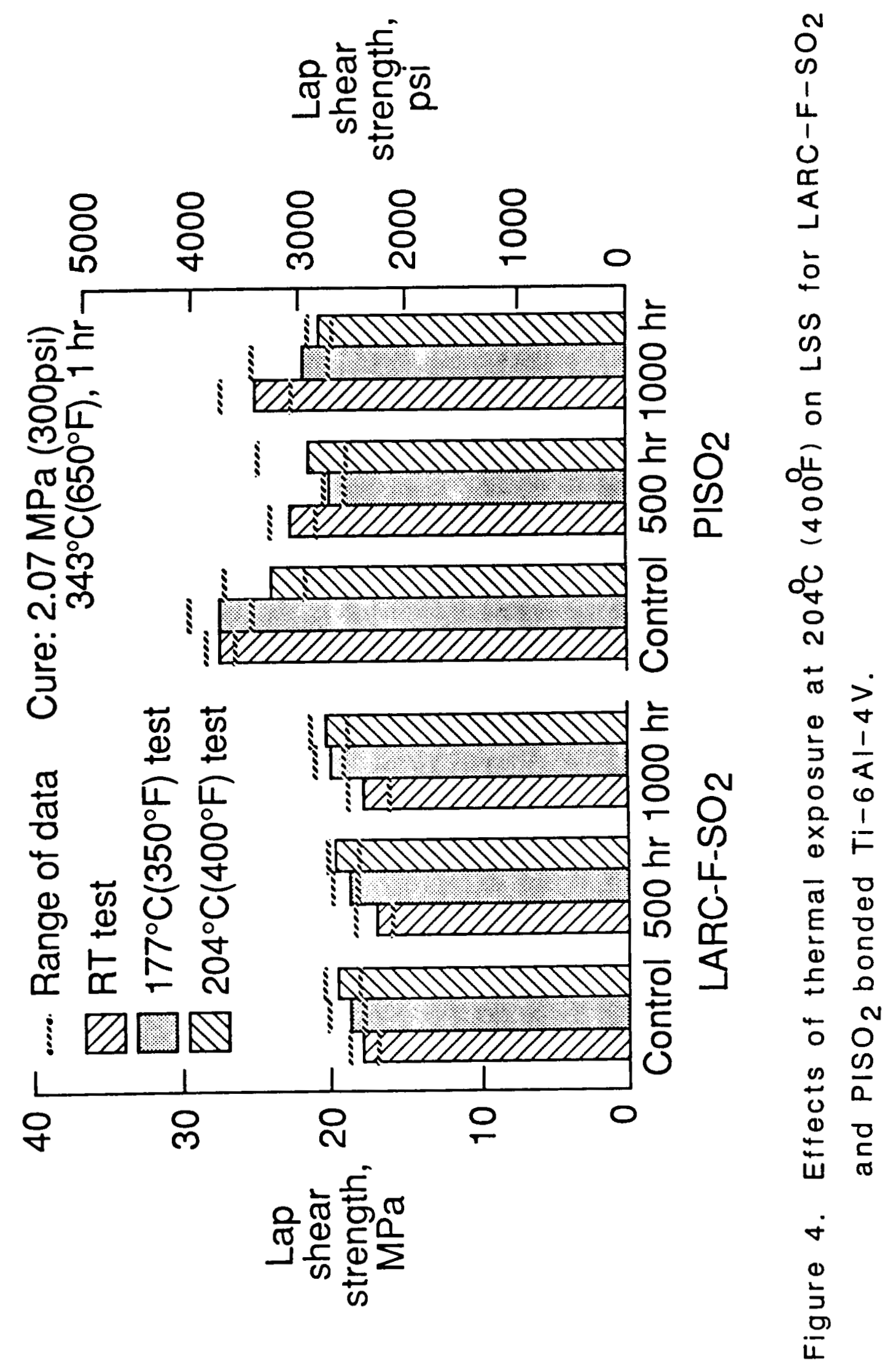




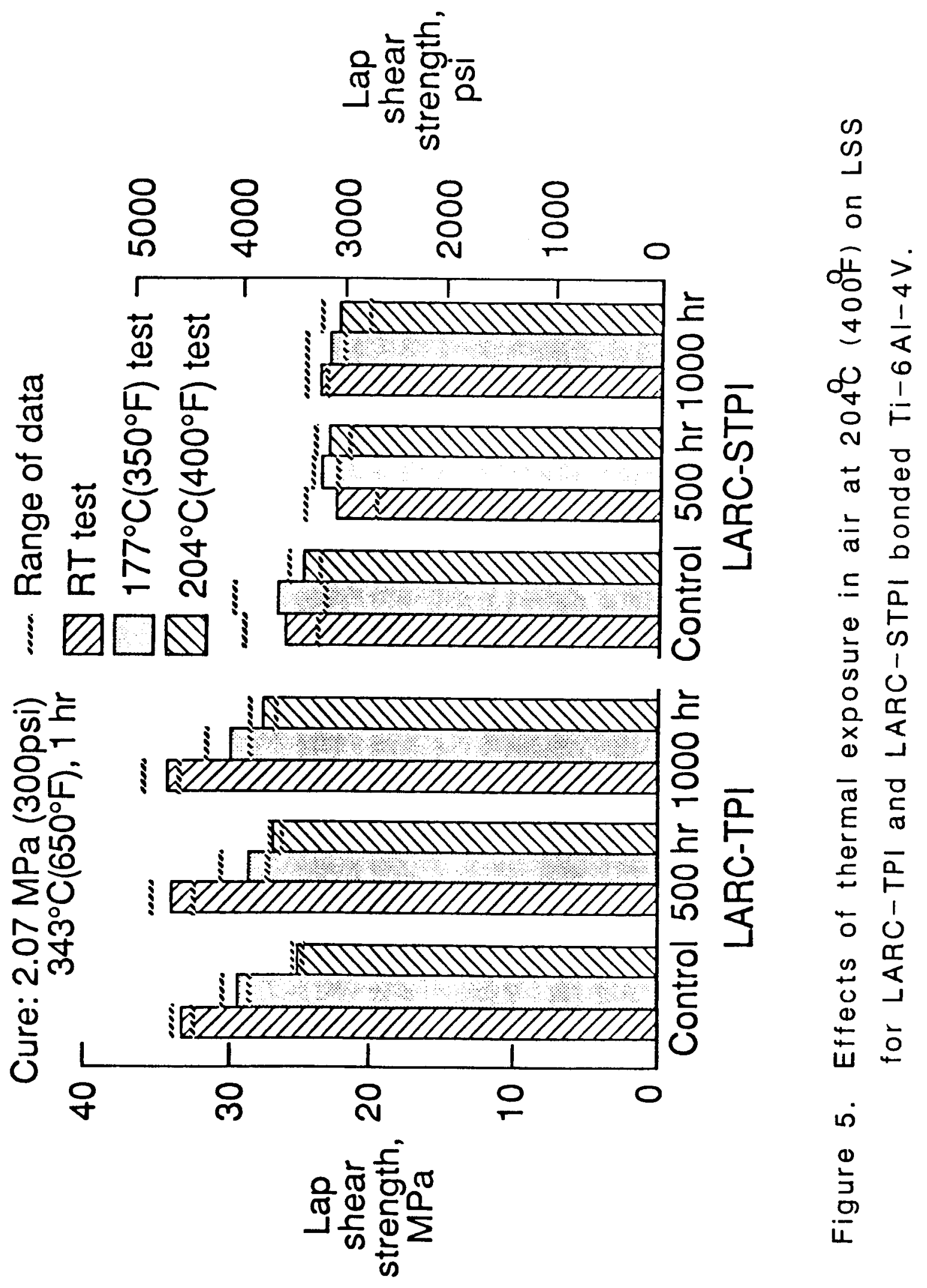




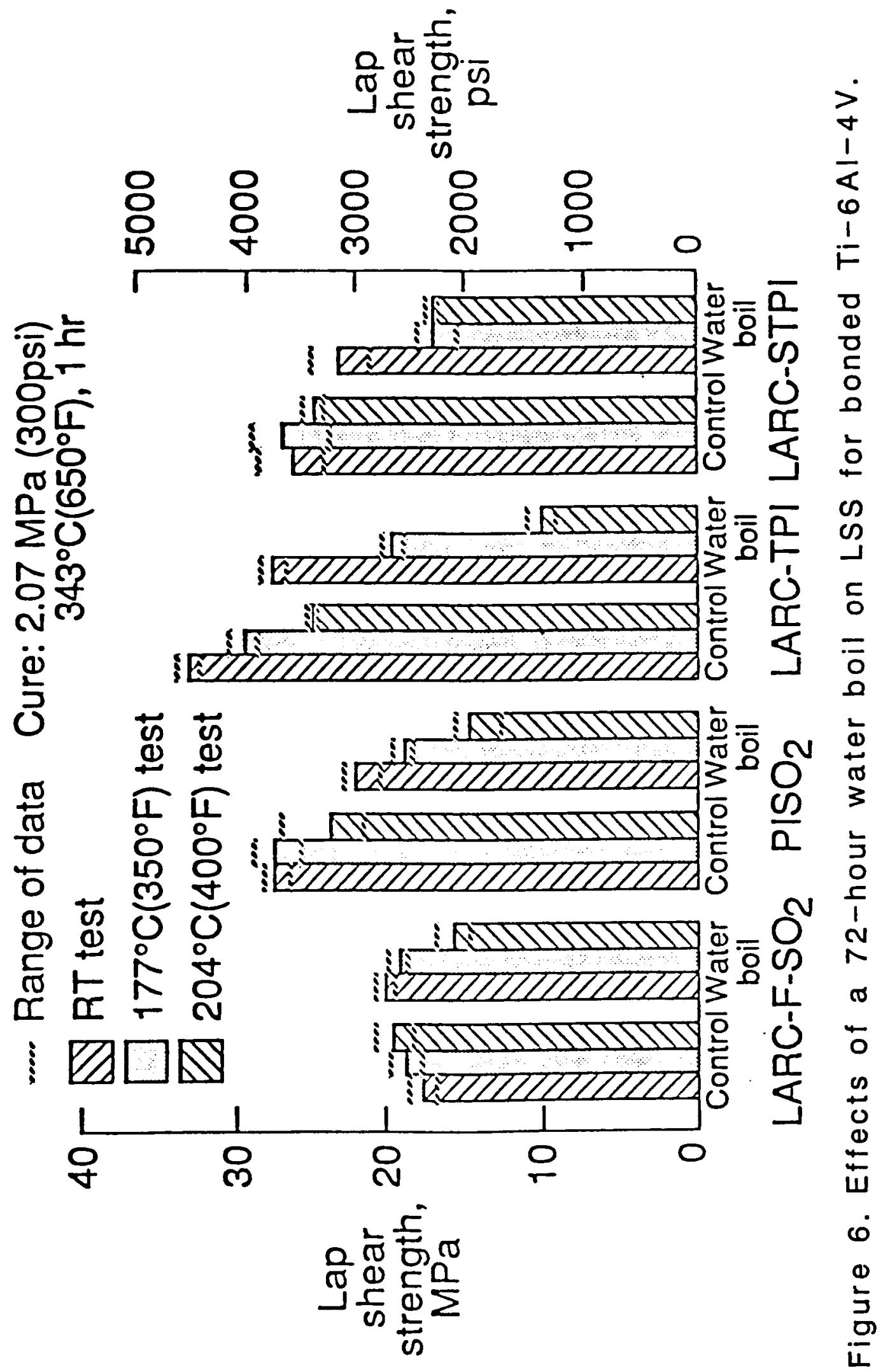


Table I.- Comparative LSS data for $\mathrm{PISO}_{2}$ and LARC-F- $\mathrm{SO}_{2}$

\begin{tabular}{|c|c|c|c|c|}
\hline Adhesive & $\begin{array}{l}\text { Bonding } \\
\text { conditions }\end{array}$ & $\begin{array}{c}\text { Test } \\
\text { temperature, } \\
{ }^{\circ} \mathrm{C}\left({ }^{\circ} \mathrm{F}\right)\end{array}$ & $\begin{array}{l}\text { Exposure time } \\
\text { at } 204^{\circ} \mathrm{C}, \mathrm{hr}\end{array}$ & $\begin{array}{c}\text { LSS, } \\
\text { MPa(psi) }\end{array}$ \\
\hline $\begin{array}{c}\text { LARC-F-SO2 } \\
\text { (present study) }\end{array}$ & $\begin{array}{c}8^{\circ} \mathrm{C} / \mathrm{min}, 2.07 \mathrm{MPa} \\
(300 \mathrm{psi}), \mathrm{RT} \text { to } 343^{\circ} \mathrm{C} \\
\left(650^{\circ} \mathrm{F}\right) \text {, hold } 1 \mathrm{hr}\end{array}$ & $\begin{array}{c}\text { RT (RT) } \\
177(350) \\
204(400) \\
\\
\text { RT (RT) } \\
177(350) \\
204(400) \\
\\
\text { RT (RT) } \\
177(350) \\
204(400)\end{array}$ & $\begin{array}{c}0 \\
0 \\
0 \\
\\
500 \\
500 \\
500 \\
\\
1000 \\
1000 \\
1000\end{array}$ & $\begin{array}{l}17.9(2600) \\
18.8(2720) \\
19.6(2840) \\
17.0(2460) \\
19.3(2800) \\
19.8(2870) \\
18.0(2620) \\
20.1(2920) \\
20.4(2950)\end{array}$ \\
\hline $\begin{array}{c}\mathrm{PISO}_{2} \\
\text { (present study) }\end{array}$ & - & $\begin{array}{c}\text { RT (RT) } \\
177(350) \\
204(400) \\
232(450) \\
\text { RT (RT) } \\
177(350) \\
204(400) \\
232(450) \\
\text { RT (RT) } \\
177(350) \\
204(400) \\
232(450)\end{array}$ & $\begin{array}{c}0 \\
0 \\
0 \\
0 \\
500 \\
500 \\
500 \\
500 \\
1000 \\
1000 \\
1000 \\
1000\end{array}$ & $\begin{array}{l}27.5(4000) \\
27.5(4000) \\
24.0(3490) \\
23.1(3340) \\
22.8(3310) \\
20.2(2930) \\
21.7(3140) \\
20.2(2940) \\
24.8(3590) \\
22.0(3190) \\
20.8(3020) \\
19.8(2870)\end{array}$ \\
\hline $\begin{array}{l}\mathrm{PISO}_{2} \\
\text { Ref. } 7\end{array}$ & $\begin{array}{c}7^{\circ} \mathrm{C} / \mathrm{min}, \mathrm{RT} \text { to } 325^{\circ} \mathrm{C} \\
\left(617^{\circ} \mathrm{F}\right) \text {, apply } 1.38 \mathrm{MPa} \\
(200 \mathrm{psi}) \text { at } 280^{\circ} \mathrm{C} \\
\left(536^{\circ} \mathrm{F}\right) \text {, hold } 325^{\circ} \mathrm{C} \\
\text { for } 15 \mathrm{~min}\end{array}$ & $\begin{array}{c}\text { RT (RT) } \\
177(350) \\
204(400) \\
232(450) \\
\text { RT (RT) } \\
204(400) \\
204(400)\end{array}$ & $\begin{array}{c}0 \\
0 \\
0 \\
0 \\
5000 \\
2500 \\
5000\end{array}$ & $\begin{array}{l}32.0(4650) \\
22.1(3210) \\
20.1(2920) \\
18.1(2620) \\
\\
20.5(2980) \\
21.9(3180) \\
20.5(2980)\end{array}$ \\
\hline $\begin{array}{l}\mathrm{PISO}_{2} \\
\text { Ref. } 9\end{array}$ & $\begin{array}{c}\text { Vaciuum, contact } \\
\text { pressure, } 4^{\circ} \mathrm{C} / \mathrm{min} \text {, } \\
\text { RT to } 343^{\circ} \mathrm{C} \\
\left(650^{\circ} \mathrm{F} \text {, apply } 0.34 \mathrm{MPa}\right. \\
(50 p s i) \text { at } 250^{\circ} \mathrm{C}\left(482^{\circ} \mathrm{F}\right) \text {, } \\
\text { after } 5 \mathrm{~min} \text { at } 343^{\circ} \mathrm{F} \text {. } \\
\text { apply } 1.38(200 \mathrm{psi}) \text {, } \\
\text { hold } 343^{\circ} \mathrm{C} \text { for } 5 \mathrm{~min}\end{array}$ & $\begin{array}{l}\text { RT (RT) } \\
232(450)\end{array}$ & $\begin{array}{l}0 \\
0\end{array}$ & $\begin{array}{l}25.2(3650) \\
19.8(2870)\end{array}$ \\
\hline
\end{tabular}




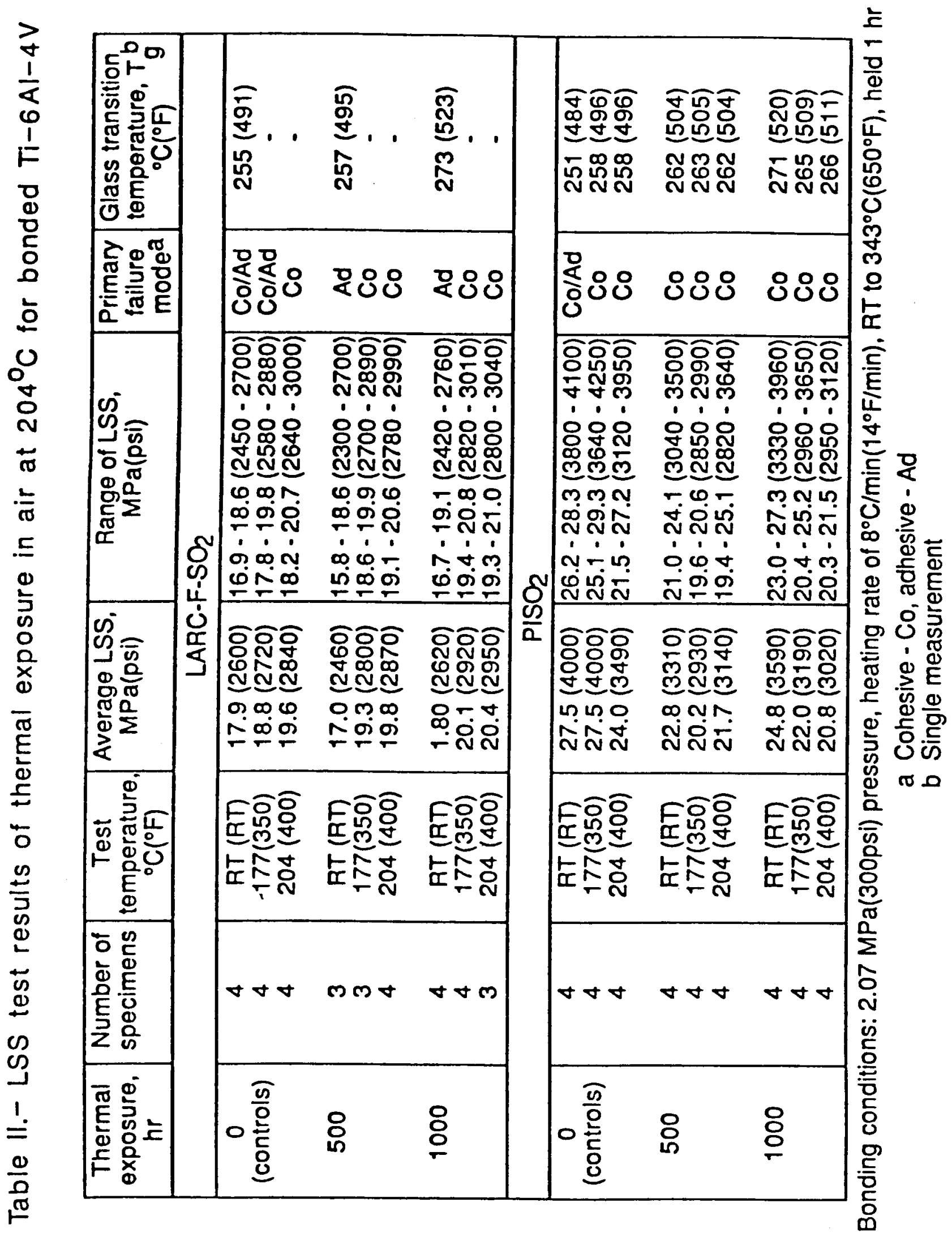




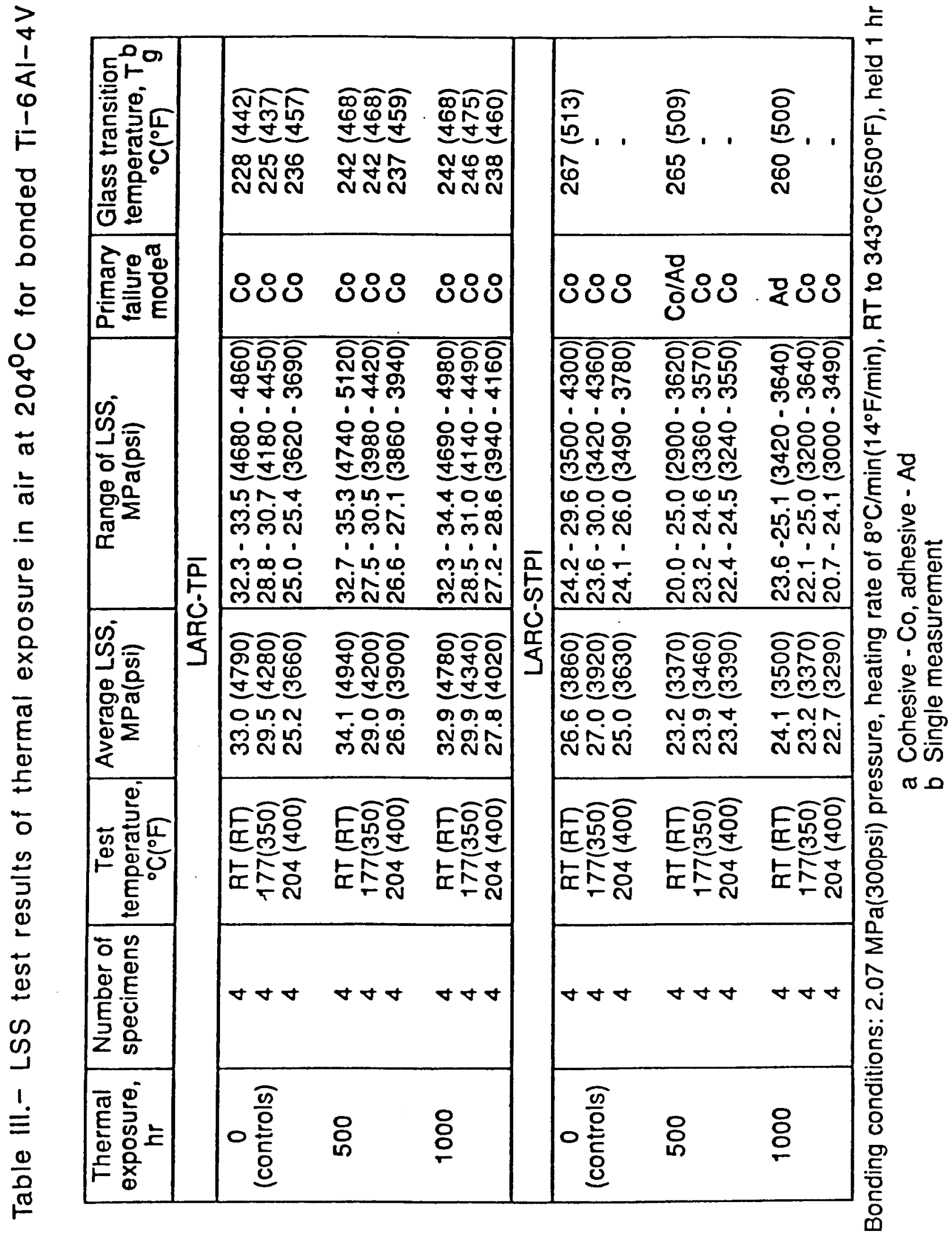




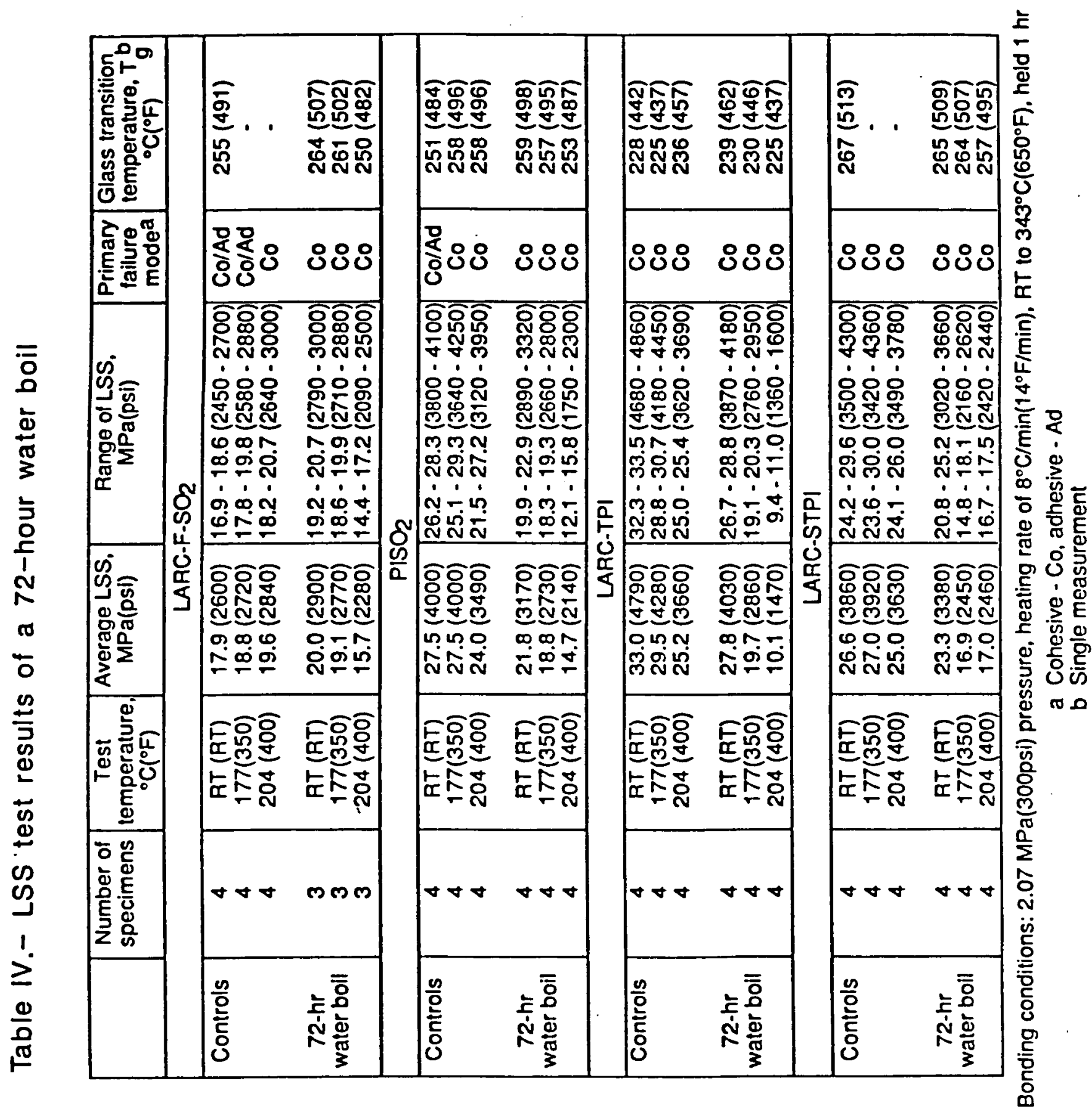




\begin{tabular}{|c|c|c|c|}
\hline 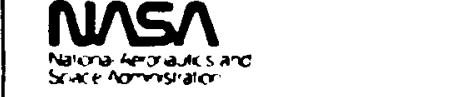 & \multicolumn{3}{|c|}{ Report Documentation Page } \\
\hline $\begin{array}{l}\text { 1. Report No. } \\
\text { NASA TM-100631 }\end{array}$ & 2. Government Accession No. & \multicolumn{2}{|c|}{ 3. Recipient's Catalog No. } \\
\hline \multirow{2}{*}{\multicolumn{2}{|c|}{$\begin{array}{l}\text { 4. Title and Subtitle } \\
\text { Flexible Backbone Aromatic Polyimide Adhesives }\end{array}$}} & \multicolumn{2}{|l|}{$\begin{array}{l}\text { 5. Repon Date } \\
\text { July } 1988 \\
\end{array}$} \\
\hline & & \multicolumn{2}{|c|}{ 6. Performing Organization Code } \\
\hline \multicolumn{2}{|l|}{ 7. Author(s) } & \multicolumn{2}{|c|}{ 8. Performing Organization Repon No. } \\
\hline \multicolumn{2}{|c|}{ Donald J. Progar and Terry L. St. Clair } & \multirow{2}{*}{\multicolumn{2}{|c|}{$\begin{array}{l}\text { 10. Work Unit No. } \\
505-63-01-01 \\
\end{array}$}} \\
\hline \multirow{3}{*}{\multicolumn{2}{|c|}{$\begin{array}{l}\text { 9. Pertorming Organization Name and Address } \\
\text { NASA Langley Research Center } \\
\text { Hampton, VA 23665-5225 }\end{array}$}} & & \\
\hline & & \multicolumn{2}{|c|}{ 11. Contract or Grant No. } \\
\hline & & \multicolumn{2}{|c|}{ 13. Type of Report and Period Covered } \\
\hline \multicolumn{2}{|c|}{$\begin{array}{l}\text { National Aeronautics and Space Administration } \\
\text { Washington, DC } 20546\end{array}$} & \multicolumn{2}{|c|}{$\begin{array}{l}\text { Technical Memorandum } \\
\text { 14. Sponsoring Agency Code }\end{array}$} \\
\hline \multicolumn{4}{|l|}{ 15. Supplementary Notes } \\
\hline \multicolumn{4}{|c|}{$\begin{array}{l}\text { Cont inuing research at Langley Research Center on the synthesis and development } \\
\text { of new inexpensive flexible aromatic polyimides as adhesives has resulted in a } \\
\text { material identified as LARC- }-\mathrm{SO}_{2} \text { with similarities to polyimidesulfone, } \mathrm{PISO}_{2} \text {, } \\
\text { and other flexible backbone polyimides recently reported by } \mathrm{Progar} \text { and } \mathrm{St}^{-} \\
\text {Clair. Also prepared and evaluated was an endcapped version of } \mathrm{PISO}_{2} \text {. These two } \\
\text { polymers were compared with LARC-TPI and LARC-STPI, polyimides researched in our } \\
\text { laboratory and reported in the literature. }\end{array}$} \\
\hline \multicolumn{4}{|c|}{$\begin{array}{l}\text { The adhesive evaluation, primarily based on lap shear strength (LSS) tests at RT, } \\
177^{\circ} \mathrm{C} \text { and } 204^{\circ} \mathrm{C} \text {, involved preparing adhesive tapes, conducting bonding studies } \\
\text { and exposing lap shear specimens to } 204^{\circ} \mathrm{C} \text { air for up to } 1000 \mathrm{hrs} \text { and to a } 72 \text {-hour } \\
\text { water boil. The type of adhesive failure as well as the Tg was determined for } \\
\text { the fractured specimens. }\end{array}$} \\
\hline \multicolumn{4}{|c|}{$\begin{array}{l}\text { The results indicate that LARC-TPI provides the highest LSSs. LARC-F- } \mathrm{SO}_{2} \text {, } \\
\text { LARC-TPI and LARC-STPI all retain their strengths after thermal exposure for } 1000 \\
\text { hrs and } \mathrm{PISO} \mathrm{O}_{2} \text { retains greater than } 80 \% \text { of its control strengths. }\end{array}$} \\
\hline \multicolumn{4}{|c|}{$\begin{array}{l}\text { After } 72-h r \text { water boil exposure, most of the four adhesive systems showed } \\
\text { reduced strengths for all test tenperatures although still retaining a high } \\
\text { percentage of their original strength }(260 \%) \text { except for one case. } \\
\text { The predominant failure type was cohesive with no significant change in the Tgs. }\end{array}$} \\
\hline \multicolumn{2}{|c|}{ 17. Key Words (Suggested by Author(s)) } & & \\
\hline $\begin{array}{l}\text { Polyimide } \\
\text { Adhesive } \\
\text { Aromatic Polyimide } \\
\text { Copolyimide }\end{array}$ & & & \\
\hline $\begin{array}{l}\text { 19. Security Clossit. lof this repori) } \\
\text { Unclassified }\end{array}$ & $\begin{array}{l}\text { 20. Security Classif. lof this page) } \\
\text { Unclassified }\end{array}$ & $\begin{array}{l}\text { 21. No. of pages } \\
29\end{array}$ & $\begin{array}{r}\text { 22. Price } \\
\text { A03 }\end{array}$ \\
\hline
\end{tabular}

